\title{
RESISTANCE SPOT WELDING CHARACTERIZATION OF PRESS HARDENED STEEL \\ ${ }^{1,2}$ Abbade, L.; ${ }^{1,2}$ Lara, J. A. C.; ${ }^{1}$ Couto, C. P.; ${ }^{1,2}$ Gonsalez, B.; ${ }^{3}$ Colosio, M. A.; ${ }^{1}$ Rossi, J. L. \\ ${ }^{1}$ Instituto de Pesquisas Energéticas e Nucleares - IPEN - CNEN/SP; \\ ${ }^{2}$ Centro Universitário Fundação Santo André \\ ${ }^{3}$ General Motors South America
}

* e-mail: Larissa-abbade@hotmail.com

\begin{abstract}
In the automotive industry the resistance spot welding (RSW) is one of the most used processes for joining steel sheets, being of fundamental importance the quality assurance of this process. In this work, 22MnB5 steel sheets for the hot stamping process, also known as PHS (Press Hardening Steel), were joined by the technique of resistance spot welding, so that the welding parameters were changed 16 times for the evaluation of the influence of these parameters on the mechanical properties. By conducting ultrasonic, tensile and hardness test, followed by metallography, it was possible to identify the characteristics of the spot weld effect on the material. The results of the tests performed in this work confirmed the difference in mechanical strength of the thermal zone (ZTA) in relation to the molten zone (ZF). For a certain set of the parameters it was shown a decrease in the strength of the ZTA and increasing to the weld point, which is demonstrated in the microstructural analysis and thus justifies the detachment of the weld button of the base material during tensile testing, i.e., there was a higher strength in the welded area.
\end{abstract}

Keywords: resistance spot welding, 22MnB5, PHS, hot stamping, press hardening.

\section{INTRODUCTION}

One of the major concerns that has been arising in recent years within the automotive industry has been making cars more sustainable, more safer and economic, due to use of less fossil fuels and governments regulation [1]. One of the methods to promote this is to use lighter materials that reduce the mass of vehicles and increase the energy absorption in collision. Decrease the amount of weld points and increase the resistance spot strength on the vehicle body in white is one way to achieve this aim [2]. The resistance spot welding technique is a process in which the surfaces of the plates are joined together by means of one or more points on which is applied heat by Joule effect and pressure [3]. The welding process, in spite of relatively old and well studied for mild steel, recently, new researches had to be conducted for the use of hot stamping steels [4]. The hot stamping has achieved success in the manufacture of parts with complex formats, showing outstanding mechanical strength and energy absorption capabilities and less weight [5].

\section{EXPERIMENTAL}

The material used for the specimens manufacture for the experiments was PHS 22MnB5 steel plates coated with Al-Si. It was used 40 samples of hot stamped plates with dimensions of $123 \times 29 \times 1.30 \mathrm{~mm}^{3} \mathrm{~mm}$. The samples named P6 and P7 are henceforth in relation to the welding parameters, for sheet heat treated on condition of patchwork and sheet with heat treatment of tempering, respectively. After the welding process in overlap condition each group remained with 10 samples, joined by a single spot weld. In Table 1 are described the welding parameters used for P6 and P7. 
The welding parameters were previously tested in order to achieve full nugget detachment.

\begin{tabular}{cccc}
\multicolumn{4}{c}{ Table1 - Parameters of resistance spot welding. } \\
\hline $\begin{array}{c}\text { Welding } \\
\text { parameters }\end{array}$ & Unit & $\boldsymbol{P 6}$ & $\boldsymbol{P 7}$ \\
\hline Pre burn current & $\mathrm{A}$ & 5 & 5 \\
\hline Pre burn time & $\mathrm{ms}$ & 60 & 60 \\
\hline Weld current & $\mathrm{A}$ & 9 & 9 \\
\hline Weld time & $\mathrm{ms}$ & 200 & 200 \\
\hline Pulse & - & 2 & 2 \\
\hline $\begin{array}{c}\text { Post heat treatment } \\
\text { current }\end{array}$ & $\mathrm{A}$ & 0 & 6 \\
\hline $\begin{array}{c}\text { Post heat treatment } \\
\text { time }\end{array}$ & $\mathrm{ms}$ & 0 & 80 \\
\hline Hold time & $\mathrm{ms}$ & 200 & 200 \\
\hline
\end{tabular}

After the resistance spot weld of the samples tensile testing, Vickers hardness measurement, ultrasonic and optical microscopy was conducted.

\section{RESULTS AND DISCUSSION}

From the analysis in Figure 1 which presents the weld spot diameters obtained through ultrasonic test, it is possible to identify the minimum and maximum values, noting that the smaller diameters were obtained in the weld P6.5.

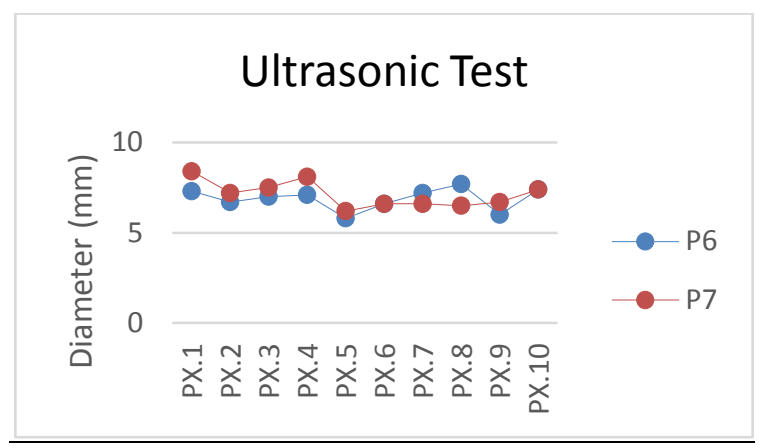

Figure 1: Diameter obtained through ultrasonic test.

Figure 2 presents the values of indention, obtained by ultrasonic test for P6 and P7. The results of indentation over $30 \%$ are not acceptable according to the AWS standard [7]. However, the tensile tests results were acceptable with no partial fracture.

Regarding the tensile testing, samples P 6.5 and P7.5 were not realized on; they were put aside for hardness testing and metallography. As shown in Table 2, for group P6, the least load bearing sample was observed for sample P 6.1, around $14 \mathrm{kN}$ and $7.30 \mathrm{~mm}$ wel spot diameter, in this group the diameter presented in P 6 the relative smaller diameter and lower load were ruled out for statistics purposes. The reduction of load bearing could be related to intermetallic of $\mathrm{Al}-\mathrm{Si}$ formation at the HAZ area.

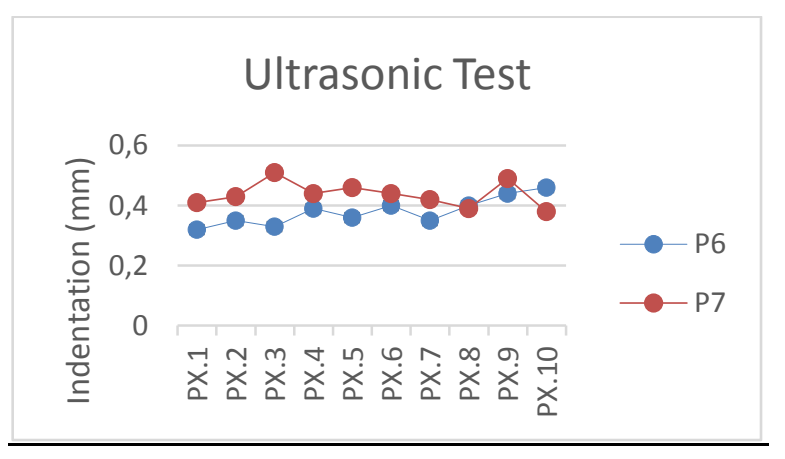

Figure 2: Indentation obtained though ultrasonic test.

Table 2 - Maximum load and weld spot diameter obtained for samples P6 group.

\begin{tabular}{ccc}
\hline ID. Sample & $\begin{array}{c}\text { Diameter } \\
(\mathbf{m} \boldsymbol{m})\end{array}$ & $\begin{array}{c}\text { Maximum } \\
\text { load }(\boldsymbol{N})\end{array}$ \\
\hline P6.1 & 7.30 & 13916 \\
P6.2 & 6.70 & 19824 \\
P6.3 & 7.00 & 14137 \\
P6.4 & 7.10 & 16973 \\
P6.6 & 6.60 & 14241 \\
P6.7 & 7.20 & 19585 \\
P6.8 & 7.70 & 15802 \\
P6.9 & 6.00 & 17505 \\
P6.10 & 7.40 & 21503 \\
\hline
\end{tabular}

For the group P7, as shown in Table 3, the weaker sample became for the sample P7.1, around $11 \mathrm{kN}$ and $8.40 \mathrm{~mm}$ diameter. It can be observed that the diameter is not the main reason of load bearing reduction.

Table 3 - Maximum load and weld spot diameter obtained for samples P7 group.

\begin{tabular}{ccc}
\hline ID. Sample & $\begin{array}{c}\text { Diameter } \\
(\mathbf{m m})\end{array}$ & $\begin{array}{c}\text { Maximum } \\
\text { load }(\mathbf{N})\end{array}$ \\
\hline P7.1 & 8.40 & 10693 \\
P7.2 & 7.20 & 15691 \\
P7.3 & 7.50 & 15142 \\
P7.4 & 8.10 & 14955 \\
P7.6 & 6.60 & 16853 \\
P7.7 & 6.60 & 15744 \\
P7.8 & 6.50 & 14425 \\
P7.9 & 6.70 & 15262 \\
P7.10 & 7.40 & 16017 \\
\hline
\end{tabular}

With maximum load values obtained in P6 and P7 groups, it was checked that all the nuggets of weld presented acceptable results even those that were not approved by AWS, as they are with the percentage of 
indentation above $30 \%$. The nugget occurred in the trials were equal to that provided for by the standard and showed that the region remain intact and the fracture occurred from a sheet tear at the base material started by ZTA (zone thermally heat affected) [7].

It was performed microhardness points, 19 on each sample, maintaining the $0.25 \mu \mathrm{m}$ distance as set out in the standard. For convenience, the measuring point 0 on the $x$-axis would be the center of the weld point, setting up 9 points to the left and 9 measuring points to the right.

In Figure 3 it can seen that there has been an increase in the hardness from the ZTA, following to the weld point, an important factor for clarification of the load beating results. It was possible to identify a size difference in the ZTA, P7.5 showed a region smaller than $P 6.5$, this variation is due to the tempering applied and offset of the Al-Si coating at P7.5.

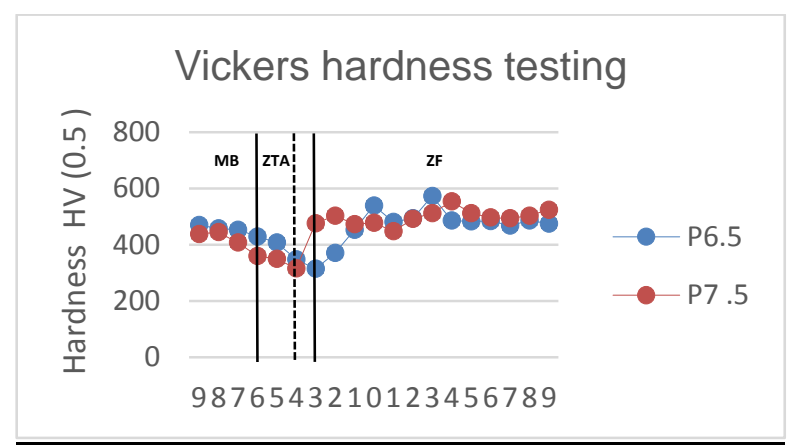

Figure 3 - Vickers hardness testing, dividing MB (base metal), ZTA (zone thermally heat affected) and ZF (melt).

To evaluate and identify the homogeneity of the weld point, the ZTA, when compared to the base metal, it was used optical microscopy (MO). In Figure 4, it is possible to identify a sudden change in the ZTA, both in the sample $P 6.5$ and $P$ 7.5, confirming also visually the detachment of weld point on the tensile testing, and low hardness. The hardness drop between the base metal and the ZTA was due to the presence of bainite, some porosity and with a string of intermetallic phase that were due to the metallic coating of the sheet, in the present case Al-Si (P 7.5) that resulted from a slow annealing in the area affecting the welded joint [2].

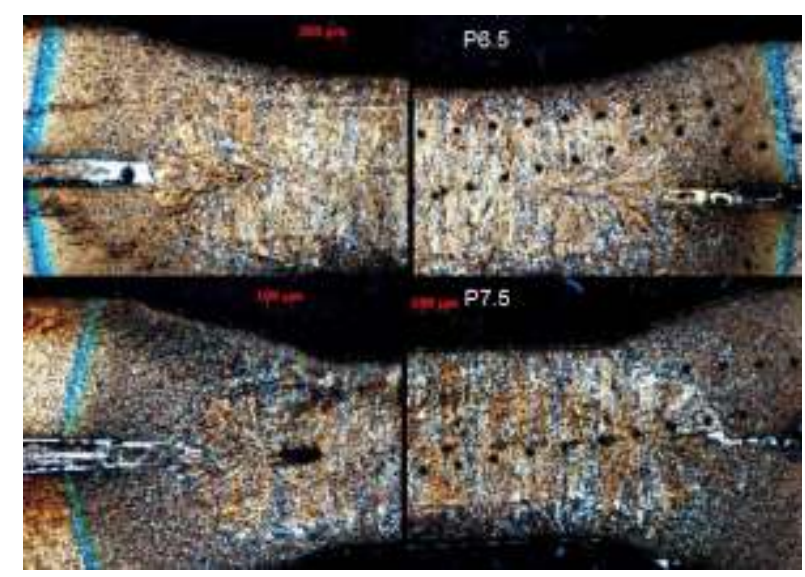

Figure 4 - Optical microscopy of samples P6.5 e P7.5 showing bainite, porosity and intermetallics.

\section{CONCLUSION}

Based on the results obtained in experiment by testing (ultrasonic, tensile, hardness test and microstructure), it was possible to analyze the difference in terms of load bearing capability of ZTA. All specimens of groups P6 and P7, showed a drop in load bearing in this region, due to an increase in pores and intermetallic phases until the weld point, therefore, justify the deployment of the nugget on the base material tensile test. Thus, it is concluded that the process of resistance spot welding is effective for hot stamping sheet metal nugget, once the welded area has attained the best performances in the weld button and even with changes of diameter and hardness, reached the expectations that enables higher-performance material usage.

\section{ACKNOWLEDGEMENT}

We would like to thank the Benteler Corporate and General Motors South America for materials supply.

\section{REFERENCES}

[1] BATISTA, M. Comparative Study of the Weldability of Sheets for the Automotive Industry Using Two Resistance Welding Equipments. Master Dissertation, University of São Paulo - USP - Brazil, 2011. (In Portuguese).

[2] MIRANDA, G. P. Resistance Point Weldability Study of 22MnB5 and DP800 Steels. Master Dissertation, Federal University of Minas Gerais, MG, Brazil, 2015. (In Portuguese).

[3] WOLFF, M. A. Weldability of Dual-Phase 600 and $\mathbf{8 0 0}$ Steels Via Medium Frequency (mfdc) and Alternating Current (ac). Federal University of Uberlandia - UFU, MG, Brazil, 2008. (In Portuguese).

[4] CHOI, H. S.; Park, G-H.; Lim, W-S.; Kim, B-M. 
Evaluation of weldability for resistance spot welded single-lap joint between GA780DP and hot-stamped 22MnB5 steel sheets. Journal of Mechanical Science and Technology, June 2011, 25(6):1543-1550, 2011.

[5] GORNI, A. A. New trends for the hot stamping process. Corte \& Conformação de Metais, June 2010, p. 62-77, 2010. (In Portuguese).

[6] HEIN, P. Numerical Simulation of the Hot Stamping of Automotive Components with Usibor 1500. In:

Communicating European Research, EuroPAM, p. 17, 2005.

[7] AWS/SAE D8.9. Recommended Practices for Test Methods for Evaluating the Resistance Spot Welding Behavior of Automotive Sheet Steel Materials. AWS, USA, 1997. 